Article

\title{
Roots of Incivility: How Personality, Media Use, and Online Experiences Shape Uncivil Participation
}

\author{
Lena Frischlich ${ }^{1,2, *}$, Tim Schatto-Eckrodt ${ }^{1}$, Svenja Boberg ${ }^{1}$ and Florian Wintterlin ${ }^{1}$ \\ ${ }^{1}$ Institute for Communication, University of Münster, 44843 Münster, Germany; \\ E-Mails: lena.frischlich@uni-muenster.de (L.F.), tim.schatto-eckrodt@uni-muenster.de (T.S.E.), \\ svenja.boberg@uni-muenster.de (S.B.),florian.wintterlin@uni-muenster.de (F.W.) \\ 2 Department of Media and Communication, University of Munich, 80538 Munich, Germany \\ * Corresponding author
}

Submitted: 15 June 2020 | Accepted: 11 September 2020 | Published: 3 February 2021

\begin{abstract}
Online media offer unprecedented access to digital public spheres, largely enhancing users' opportunities for participation and providing new means for strengthening democratic discourse. At the same time, the last decades have demonstrated that online discourses are often characterised by so-called 'dark participation' the spreading of lies and incivility. Using 'problematic behaviour theory' as framework and focusing on incivility as a specific form of dark participation, this article investigates the role of users' personal characteristics, media use, and online experiences in relation to offensive and hateful online behaviour. Using a random-quota survey of the German population, we explored how dark personality traits, political attitudes and emotions, the frequency and spaces of online-media use, and users' experiences with both civil and uncivil online discourses predicted participants own uncivil behaviour, such as posting, sharing, or liking uncivil content. We found that $46 \%$ of the participants who had witnessed incivility in the last three months also engaged in uncivil participation. A hierarchical logistic regression analysis showed that incivility was associated with manipulative personality traits as measured by the dark triad, right-wing populist voting intentions, and frequent social-media use. Experiences with both civil comments and hate speech predicted higher levels of uncivil participation. The strongest predictor was participants' personal experiences with online victimisation. Overall, the results confirmed that dark participation in the sense of uncivil engagement results from the interplay of personality traits, an online environment that allows for deviant engagement, and, most importantly, participants' experiences in said environment.
\end{abstract}

\section{Keywords}

dark participation; dark triad; hate speech; incivility; offensive speech; personality; political anger; problematic behaviour theory; social media; victimisation

\section{Issue}

This article is part of the issue "Dark Participation in Online Communication: The World of the Wicked Web" edited by Thorsten Quandt (University of Münster, Germany).

(C) 2021 by the authors; licensee Cogitatio (Lisbon, Portugal). This article is licensed under a Creative Commons Attribution 4.0 International License (CC BY).

\section{Introduction}

Online media provide unprecedented access to digital public spheres. While the eased access to digital public spheres offers new possibilities for deliberative participation (Shane, 2004), it also provides new opportunities for so-called 'dark participation' (Quandt, 2018, p. 36), norm transgressing forms of online engage- ment, which includes acts such as spreading disinformation and/or uncivil and hateful content. Most citizens in Western democracies report experiences of online incivility (Geschke, Klaßen, Quent, \& Richter, 2019). Witnessing online hate contributes to political polarisation (Hwang, Kim, \& Huh, 2014), jars social trust (Näsi, Räsänen, Hawdon, Holkeri, \& Oksanen, 2015), fuels discrimination (Hsueh, Yogeeswaran, \& Malinen, 2015), 
and reduces pro-social activities addressing minorities (Ziegele, Koehler, \& Weber, 2018). So far, comparably little is known about the factors motivating individuals' uncivil online behaviour. Our study aims to fill this gap. Using Germany, the first country in the world with a legal framework for dealing with deviant online engagement (the so-called network enforcement act), as context and data from a random-quota survey $(N=5000)$, we aimed to answer the following overarching question: Which factors motivate uncivil participation?

\section{Dark Participation and Incivility}

Dark participation describes an online setting whereby (a) wicked actors (individuals, groups, and state actors), driven by (b) sinister strategical, tactical, or "pure evil" (Quandt, 2018, p. 41) motives, attack (c) despised objects/targets either directly or indirectly with the aim of (d) manipulating different audience(s). In broader terms, dark participation can be understood as normtransgressing participation that violates either the norms of civil discourse (i.e., by name-calling or using racial slurs) or honesty (i.e., by spreading falsehoods). Our study focuses on the first type of dark participation: incivility.

Incivility is a "notoriously difficult term to define" (Coe, Kenski, \& Rains, 2014, p. 660). While there is a consensus that incivility can be understood as normtransgressing communication (Kenski, Coe, \& Rains, 2020; Mutz, 2015; Papacharissi, 2004), it is less clear which norms are being transgressed. At least two types of norms need to be distinguished: norms related to interpersonal communication and norms related to intergroup communication. Muddiman (2017) refers to these two types as transgressions of personal norms"Communication that violates the norms of politeness" (Mutz, 2015, p. 6)-and transgressions of public normsmessages that "threaten a collective founded on democratic norms" (Papacharissi, 2004, p. 271). Gagliardone et al. (2016, p. 19) suggested labelling the first type as 'offensive speech,' often studied under labels like 'flaming' (e.g., O'Sullivan \& Flanagin, 2003), 'trolling' (Buckels, Trapnell, \& Paulhus, 2014), or 'cyber-bullying' (e.g., Festl, 2016; van Geel, Goemans, Toprak, \& Vedder, 2017), and the second type as 'hate speech' (Silva, Mondal, Correa, Benevenuto, \& Weber, 2016) intersecting with phenomena such as discrimination, racism, or 'group-focussed enmity' and sometimes characterized as 'harmful' or 'dangerous speech' (for an overview, see Kümpel \& Rieger, 2019), a distinction we will also use throughout this article.

Complicating the definition of incivility further, online norms are context-dependent (Coe et al., 2014). What is considered acceptable on message boards like 4Chan (Hine et al., 2016) might be inappropriate in a public Facebook group. Plus, as O'Sullivan and Flanagin (2003) argue, there is a sender, a receiver, and an observer perspective involved in detecting norm viola- tions. Messages can be intentionally norm-transgressing or not and can be classified as such by an observer or the target. Consequently, "Incivility is very much in the eye of the beholder" (Herbst, 2010, p. 3). Finally, incivility uses multiple channels. Although much research has focused on text-based incivility (e.g., Stroud, 2010), uncivil communication can also use images as well as audio or video material (Kümpel \& Rieger, 2019).

With this context in mind, the current article focuses on uncivil participation that (a) entails offensive speech and hate speech, (b) in online media channels using different forms (e.g., video or text), and (c) is perceived as mocking or attacking the target by the perpetrator (though might not be intended to harm).

\section{Problematic Behaviour Theory and Uncivil Participation}

Jessor's problematic behaviour theory (1991; Jessor \& Jessor, 1977) argues that norm-transgressing behaviour, such as uncivil participation, results from the interplay between a person's characteristics, his or her environment, and, most importantly, that person's perceptions of said environment. Traditionally, problematic behaviour theory distinguishes the following three systems: the 'personality system' (including beliefs and attitudes); the 'environmental system' (including the 'social system,' such as one's peers or parents); the 'perceived environment' (i.e., the norms within that system); which all influence a forth system, namely the 'behaviour system,' which involves a covariation of different normtransgressing problematic behaviours. The theory has been developed and employed mostly in the context of (adolescent) norm-deviances (e.g., alcohol abuse as examined in Hays, Stacy, \& di Matteo, 1987; for a review of the theories' application, see Jessor, 2017), but there is also scholarship arguing that problematic behaviour theory provides a useful perspective on online behaviour (De Leo \& Wulfert, 2013; Lee, Kim, Hong, \& MarsackTopolewski, 2019).

Most of the scholarship on problematic behaviour theory employed a developmental perspective, underlining the role of family values and peers. However, scholarship on online incivility suggests that personality and the perceived environmental system are valuable organising structures for adults' online behaviour as well. In a recent overview, Kümpel and Rieger (2019) have identified two main drivers of uncivil online discourses: the characteristics of the sender (e.g., their personality, attitudes, and emotions) and the online environment (e.g., the attention-driven social-media logic). In addition, theories of computer-mediated communication, such as the 'social identity deindividuation' framework (Postmes, Spears, \& Lea, 1998), have argued that perceptions of the online realm matter for behaviour in that realm. Accordingly, we will review prior research on incivility by using an adapted version of the problematic behaviour theory and distinguishing between variables 
related to the personality system, participants' social online environment, and their experiences in and perceptions of this environment.

\subsection{The Personality System}

\subsubsection{Dark Personality}

Norm-transgressing behaviour has been frequently associated with the so-called 'dark triad.' The dark triad describes three sub-clinical forms of offensive personalities: 'narcissism,' 'Machiavellianism,' and 'psychopathy' (Paulhus \& Williams, 2002). Although all three covary, they are not superimposable. Narcissists are characterised by grandiosity perceptions, a belief in their own superiority (Paulhus \& Williams, 2002), social manipulativeness and a lack of empathy (Raskin \& Hall, 1981). Machiavellianism involves manipulative and cold behaviour and psychopathy impulsive and thrillseeking behaviour by individuals showing reduced levels of empathy and anxiety (Paulhus \& Williams, 2002). The dark triad is associated with uncivil forms of behaviour (Kurek, Jose, \& Stuart, 2019), such as trolling (Buckels et al., 2014) and bullying (van Geel et al., 2017). However, Koban Stein, Eckhardt, and Ohler (2018) found no statistically significant association between the dark triad and intentions to comment in an uncivil manner. We thus formulated our first research question openly:

RQ1. Does the dark triad predict uncivil participation?

\subsubsection{Political Attitudes and Political Emotions}

In a series of interviews with users who produce hate speech, Erjavec and Kovačič (2012) identified ideological motivations, like defending one's ingroup against a perceived enemy, as the core characteristics of a certain type of uncivil actors, the so-called "believers." For the current study, we focused on the following three aspects of ideological motivations: 'political ideology' and political frustration as indicated by participants' 'political anger' and their feelings of 'political inefficacy' (i.e., the feeling that they are unable to influence political decision-making processes using norm-consistent forms of participation). Both anger and inefficacy have been linked to norm-deviant behaviour in collective-action research (Becker \& Tausch, 2015).

For political ideology, we looked at the extremity of political leanings and voting intentions. Extreme political leanings correlate strongly with partisan identification and reflect a polarisation of attitudes (Jost, 2017). Polarisation, in turn, is correlated with uncivil participation (Suhay, Blackwell, Roche, \& Bruggeman, 2015). We thus formulated the following hypothesis:

H1. The extremity of political attitudes predicts higher levels of uncivil participation.
In addition to extreme political leanings, right-leaning audiences could be particularly prone to uncivil discourses. US data show that conservatives generally evaluate hateful posts as being less disturbing than do the democrats (Costello, Hawdon, Bernatzky, \& Mendes, 2019). Although this lack of sensitivity might be related to white male republicans being less seldomly attacked online, conservatives are also more single-minded and have grown more extreme over time, arguing for underlying ideological asymmetries (Jost, 2017). In Germany's multi-party system, incivility has been linked to followers of the right-wing party 'Alternative for Germany,' AfD (Kreißel, Ebner, Urban, \& Guhl, 2018) and right-leaning politicians (Jaki \& Smedt, 2019), although there are also isolated incidents of conservative politicians contributing to uncivil discourses-for instance, the current state president of Bavaria, Markus Söder, derogated refugees as "asylum tourists" in 2018 (for a media report, see dpa, 2018). We thus formulated the following hypothesis:

H2. Voters of right-wing populists and conservative parties are more likely to engage in uncivil participation.

Expressions of incivility (e.g., the use of slurs, see Coe et al., 2014) tend to mirror expressions of anger. According to the cognitive-functional model of emotions, anger arises from demeaning offenses or goal-blockage, creating a sense of injustice and motivating retributive action (cf. Nabi, 2002). It is thus not surprising that anger fuels users' incivility (Gervais, 2016). Although the relationship between incivility and anger is most obvious in offensive speech, Fischer, Halperin, Canetti, and Jasini (2018) have argued that anger is also functionally related to hate. Like anger, hate emerges when a situation is perceived as being unjust and powerful figures are perceived as responsible for the anger-evoking state. We thus expected that anger, more precisely anger against the government, might be associated with uncivil participation more generally:

H3. Political anger predicts higher levels of uncivil participation.

Related to this assumption, we expected that perceived political inefficacy also plays a role in fuelling incivilities. People who perceive themselves as inefficient in a political system are less likely to engage in normative political behaviours, such as voting (Finkel, 1985), and more likely to engage in norm-deviant forms of participation (Becker \& Tausch, 2015). We thus expected that people who felt unable to influence political conditions would be more likely to express themselves in an uncivil manner:

H4. Perceived political inefficacy predicts higher levels of uncivil participation. 


\subsection{The Social Environment}

As our research focused on online incivility, we first and foremost focused on the online realm as the relevant 'social-environmental' system (Jessor, 2014). More time spent online and the use of specific social media formats is associated with a higher likelihood of encountering uncivil content (Barnidge, Kim, Sherrill, Luknar, \& Zhang., 2019; Koban et al., 2018; Oksanen, Hawdon, Holkeri, Näsi, \& Räsänen 2014), making it plausible that this is also the case with uncivil behaviour. Hence, we formulated the following hypothesis:

H5. Frequent use of online media, particularly of social media, predicts higher levels of uncivil participation.

Besides the mere time spent online, concrete virtual spaces are also likely shape uncivil online behaviour. In their examination of adolescents' contact points with specifically harsh forms of incivility, extremism, Reinemann, Ninierza, Fawzi, Riesmeyer, and Neumann (2019) found that social-networking sites are the largest contact point. However, little is known about the specific social-networking sites that people use to act uncivilly. Therefore, we formulated the following research question:

RQ2. Which social-networking sites are associated with uncivil participation?

\subsection{The Perceived Environment}

Problematic behaviour theory assumes that environmental norms guide behaviour. As the social-identity de-individuation model argues, this can be particularly true for online media (Postmes et al., 1998). We thus expected that observing civil online behaviour would be associated with less uncivil participation and observing incivility with more uncivil participation. Observing civil interactions might even reduce the impact of incivility by breaking 'hate norms.' Evidence supporting this expectation comes from research showing that counter-speech can re-civilise online discourses (Garland, Ghazi-Zahedi, Young, Hébert-Dufresne, \& Galesic, 2020; Ziegele, Jost, Frieß, \& Naab, 2019). Overall, we formulated the following two hypotheses:

H6. Exposure to civil speech predicts lower levels of uncivil participation.

H7. Exposure to uncivil speech predicts higher levels of uncivil participation.

Research using the problematic behaviour theory to explain (cyber-)bullying showed that being a victim is a strong predictor for future aggression. Although one might argue that being victimized can lead to a variety of outcomes, research on media violence has shown that victimisation (e.g., through parental aggression or abuse) is a crucial factor in predicting violent behaviour (e.g., Ferguson et al., 2008). Victimised and bullied children are likely to become aggressors themselves, although some do escape the spiral of aggression (Davis, Ingram, Merrin, \& Espelage, 2020). We thus predicted the following:

H8. Personal victimisation predicts higher levels of uncivil participation.

Figure 1 summarises our assumptions.

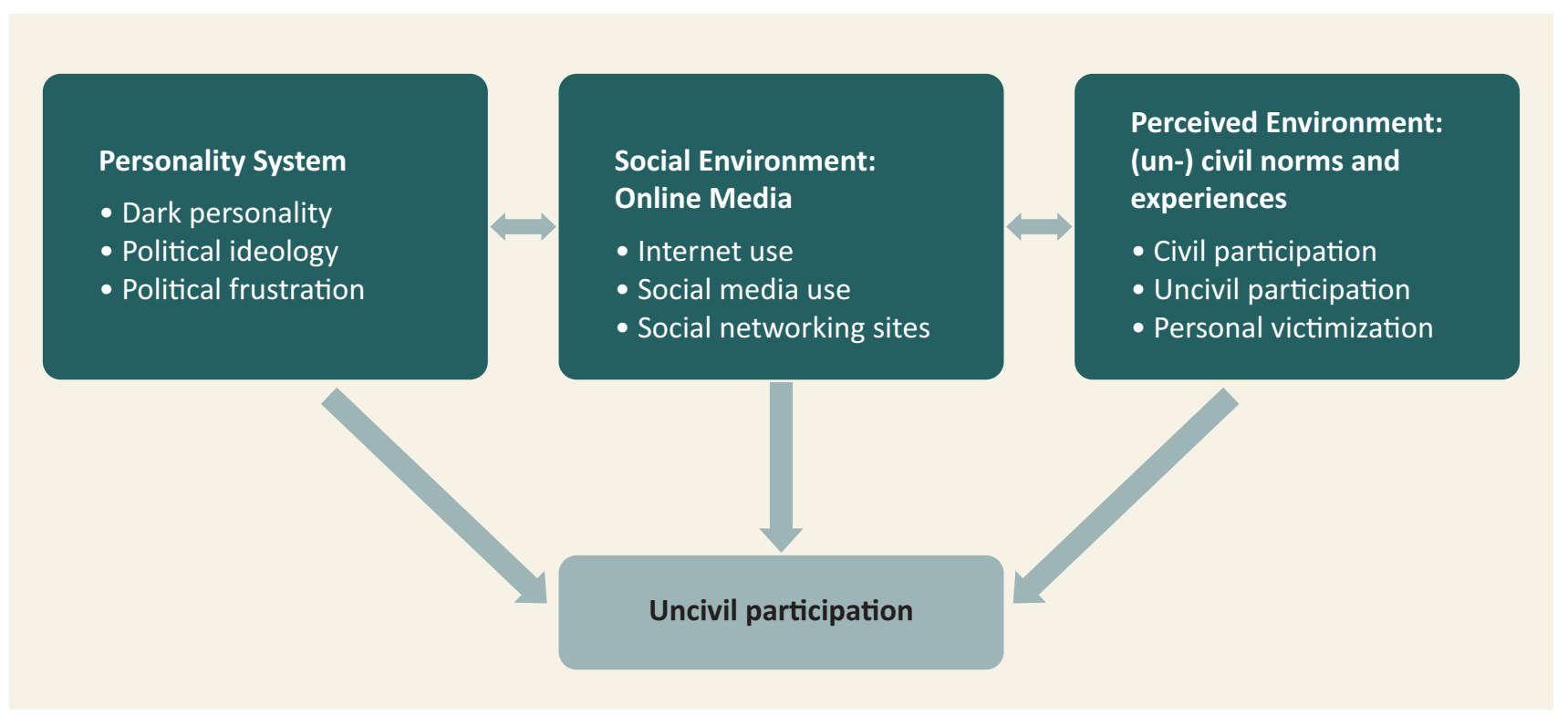

Figure 1. Predictors of uncivil online behaviour. 


\section{Methods and Measurements}

The data for this study were collected by Kantar Emnid via a random-quota web-based survey during the first two weeks of September 2017. The questions of interest were embedded in a larger survey covering sociodemographics, media use, personality traits, experiences with different types of online content, political attitudes, and voting intentions. Our analysis focuses on the variables theoretically hypothesised to motivate uncivil participation.

\subsection{Sample}

A total of 5,000 individuals finished the survey, representing the German population in terms of age, gender, and region. As it is typical for online surveys, the sample population was slightly more educated than the general population, corresponding to the overall larger online activity by those with a higher formal education (Statistisches Bundesamt, 2020). As we were interested in participants' behavioural responses to uncivil material, only the participants who had witnessed at least one type of uncivil user-generated content (i.e., hate speech or offensive speech) were included in the main analysis ( $n=2,968$, $59 \%$ of the entire sample). This selection was necessary as we asked participants whether they liked, shared, and created uncivil online content that had encountered (see section 4.2 .4 ). As only $0.05 \%$ of the participants stated that they had created uncivil content without witnessing it, we are confident that our selection did, indeed, narrow down the sample of interest. The analysed subsample was largely comparable to the overall sample, although the participants who had witnessed uncivility reported higher levels of political anger, were less likely to have a low educational status or income, and reported higher levels of online media use, matching prior research about factors leading to hate speech exposure (e.g., Costello,Barret-Fox, Bernatzky, Hawdon, \& Mendes, 2020).

\subsection{Measurements}

\subsubsection{Personality System Variables}

We measured the dark triad using the 9-item German short-scale by Küfner, Dufner, and Back (2014). The scale is a psychometrically optimised and translated version of the international Dirty Dozen scale (Webster \& Jonason, 2013), which has been demonstrated to have good structure, internal consistency, and stability (Küfner et al., 2014). Three items measured everyday psychopathy (e.g., "I tend to not feel remorse"), narcissism (e.g., "I tend to want to be admired by others") and Marchiavellism ("I deceived and lied to get my way"), respectively. To ensure consistency across the survey, all items were answered using 5-point scales ( 1 = "absolutely does not apply," 5 = "absolutely applies").
We measured political ideology by combining participants' attitudes and extremity of political leanings. Political attitudes were measured via participants' voting intentions for either of the large parties running for government at that time. Extreme political leanings were measured by coding the distance to the scale mean of the political ideology scale, resulting in a new 5-point scale $(0=$ "non-extreme," encompassing former values 5 and 6, 4 = "extreme," encompassing former values 1 and 10).

We measured political anger using three items modelled after Stürmer and Simon (2009), using the following questions "How angry/furious/irritated are you about the politics of the current government?" We measured political inefficacy using two items from Zick, Küppers, and Hövermann (2011): "Politicians do not care about people like me" and "People like me have no control over what the government does." All items were answered on a 5-point scale.

We further controlled for gender, age, education, income, and-due to large political differences between the former Eastern and Western parts of Germany where the study took place-region.

\subsubsection{Social-Environment Variables}

We measured participants' engagement with the online environment by asking participants about how much time they spent using the Internet in a normal week (hours and minutes) and their subjective social media usage ( $1=$ "never," $5=$ "always"). Furthermore, we provided the participants with a list of the most prominent social-networking sites in Germany (Schröder, 2016)-Facebook, Odnoklassniki, Twitter, Instagram, VKontakte, Pinterest, Tumblr, Reddit, LinkedIn, and Xing-and asked whether they had a social media account that they used at least occasionally (dummy coded: 1 = active user, $0=$ non-user). Tables 1 and 2 summarise the descriptives.

\subsubsection{Perceived-Environment Variables}

Before asking the participants about their experiences with civil and uncivil participation, we explained our definition of user-generated content using the following statement:

The next step is about your experiences with usergenerated content on the Internet in the last three months. User-generated content is everything that private individuals publish on the Internet. This can include text, images, or videos, for example in social media, on websites, or in the comment sections of online newspapers.

We then asked the participants about their experiences with different forms of participation, always using a 5-point scale ( 1 = "never," 5 = "at least once per day"). 
Table 1. Descriptives and reliabilities for parametric variables.

\begin{tabular}{llcc}
\hline & $\alpha$ & $M$ & $S D$ \\
\hline Age & - & 42.57 & 15.9 \\
Machiavellianism & .77 & 1.98 & 0.92 \\
Psychopathy & .82 & 1.91 & 0.93 \\
Narcissism & .87 & 2.28 & 1 \\
Extreme political leanings & - & 1.05 & 1.24 \\
Political anger & .95 & 3.27 & 1.11 \\
Political inefficacy & .79 & 3.51 & 1.07 \\
Internet use per day (in hrs) & - & 2.4 & 2.43 \\
Social-media use & - & 3.97 & 1.33 \\
\hline
\end{tabular}

Civil participation was measured with a single item:

Some user-generated content discusses political and social issues in an objective and helpful way. How often have you seen such contributions, pictures, or videos on political or social topics on the Internet in the last three months?

Incivility as offensive speech (explained as "usergenerated content [that] mocks or attacks someone personally, insults, or abuses him or her") and as hate speech ("user-generated content [that] attacks some- one because he or she belongs to a certain group") were measured using multiple items. Offensive speech was divided into personal victimisation and observed attacks on other users, journalists, or politicians. Hate speech was measured via attacks on people based on their gender, sexual orientation, skin colour, religion or nationality, political attitude, relationship with refugees, relationship with nature and animals (e.g., their diet), and fandom. A polychoric factor analysis identified three underlying factors, jointly explaining $83 \%$ of the variance. All items measuring hate speech loaded onto the first factor (Cronbach's $\alpha=.97$ ), and all items measuring

Table 2. Frequencies for dummy-coded categorical variables.

\begin{tabular}{|c|c|c|}
\hline & Yes & $\%$ \\
\hline Male & 1,622 & 51.4 \\
\hline East German & 392 & 12.4 \\
\hline Low education & 1,399 & 44 \\
\hline High education & 756 & 24 \\
\hline Low income & 1,399 & 44.3 \\
\hline High income & 769 & 25.1 \\
\hline Facebook & 2,217 & 77.9 \\
\hline Odnaklassniki & 113 & 3.97 \\
\hline Twitter & 600 & 19 \\
\hline VKontakte & 108 & 3.79 \\
\hline Instagram & 816 & 28.7 \\
\hline Pinterest & 631 & 20 \\
\hline Tumblr & 191 & 6.71 \\
\hline Reddit & 129 & 4.53 \\
\hline Linkedln & 296 & 10.4 \\
\hline Xing & 517 & 18.2 \\
\hline Alternative for Germany (AFD) voter & 349 & 11.7 \\
\hline Christian Democratic Union (CDU) & 517 & 17.3 \\
\hline Christian Social Union (CSU) voter & 123 & 4.12 \\
\hline Social Democratic Party (SPD) voter & 519 & 16.35 \\
\hline Green voter & 194 & 6.5 \\
\hline Left voter & 337 & 11.3 \\
\hline Free Democratic Party (FDP) voter & 216 & 5.36 \\
\hline Witnessed civic participation & 2,753 & 87.3 \\
\hline Witnessed offensive speech & 2,692 & 85.3 \\
\hline Witnessed hate speech & 2,902 & 100 \\
\hline Personally victimised & 887 & 28.1 \\
\hline
\end{tabular}


observed offensive speech loaded onto the second factor (Cronbach's $\alpha=.94)$. Personal victimisation was the only item loading onto the third factor, although it also loaded onto the second one. As this pattern was compatible with our theoretical assumptions that observing incivility has a different impact on the individual compared to experiencing victimisation oneself (see also Geschke et al., 2019), we used personal victimisation as a single item for the subsequent analyses. As the distribution for all exposure items was u-shaped, we formed dummy-coded variables representing exposure.

\subsubsection{Uncivil Participation}

Based on research that recommends behaviour-based measures for norm-transgressing online behaviour to reduce social-desirability bias (Festl, 2016), we asked the participants, "If you take all the comments together that mock, insult, abuse, or threaten someone, how often in the last three months did you" followed by eights statements representing positive responses to uncivil content ("evaluate such posts, images, or videos positively [e.g., via "likes" or positive comments]?) and negative reactions (e.g., "reported such a post, image, or video"). A polychoric factor analysis identified four underlying factors, explaining $81 \%$ of the variance.

Our study focuses on uncivil participation, such as liking, sharing, or producing uncivil content. All items representing this kind of behaviour loaded onto the same factor (44\% variance explanation, Cronbach's $\alpha=.96$ ). The other three factors were countering (two items, "disliking" and "commenting," 19\% variance explanation, Cronbach's $\alpha=.90$ ), ignoring (one item, 14\%), and avoiding (one item, 5\%). Two items ("reporting" and "consuming") showed cross-loadings and were thus excluded from the scale construction. Although our article focuses only on factors associated with uncivil participation, the inclusion of negative responses allowed us to provide a more natural image of the behavioral options in the current media environment.

As the distribution for the single uncivil behaviours and the sum score of the factor was highly positively skewed and mean aggregation did misrepresent such distributions, we dummy-coded whether participants had engaged in uncivil behaviour for the following analyses. Overall, $46 \%$ of those who had seen uncivil content admitted amplification (corresponding to roughly one quarter of the overall population when those who had never seen any kind of incivility and were accordingly not able to "like" or "share" this kind of material were also considered.

\section{Results}

\subsection{Analytical Approach}

We used R (Version 3.5.1; R Core Team, 2018) for all our analyses. $7 \%$ of the variables had at least one miss- ing value. Based on preliminary inspections, missing values were treated as missing at random and imputed using the MissForest algorithm. MissForest is an iterative imputation procedure based on the random forest algorithm (Stekhoven \& Buehlmann, 2012). All analyses were based on this imputed data set. To account for the different scale levels, parametric variables were mean-centred before the main analysis.

\subsection{Preliminary Analyses}

A preliminary inspection of the zero-order correlations found no statistically significant associations between uncivil participation and the German region, low income, or low education (see Table 3), and we removed these variables from the subsequent analyses. As income and education were perfectly correlated (see Supplementary File, Table A), we included only high education in the next step to avoid multi-collinearity.

\subsection{Main Analysis}

We tested our hypotheses using a logistic hierarchical regression analysis. Parametric variables were meancentred. The variables of the personality system were entered first. Block 1 included the socio-demographics and Block 2 the dark triad. Block 3 included political ideology (i.e., voting intentions and extreme political leanings) and Block 4 political frustration (anger and inefficacy). The variables related to the online environment were entered in Block 5, and the variables related to the perceived environment in Block 6.

As all blocks reached statistical significance, we focused on the last block to evaluate our hypotheses. This allowed us to examine all predictor variables in concert, thus reflecting the logic underlying problematic behaviour theory (Jessor, 1991). Block 6 explained $34 \%$ of the variance. All socio-demographic control variables failed to reach statistical significance. Answering RQ1, the dark personality traits Machiavellianism and psychopathy, though not narcissism, were associated with a higher likelihood of uncivil participation. Extreme political leanings did not predict uncivil participation $(\mathrm{H} 1)$ but, partially confirming $\mathrm{H} 2$, intentions to vote for the AfD did. Voting for conservative parties (CDU and CSU) did not predict uncivil participation, and neither did political anger ( $\mathrm{H} 3$ ) or political inefficacy $(\mathrm{H} 4)$. Although general Internet use was not predictive of uncivil participation, the subjective frequency of social media use and using VKontakte were (H5, RQ2). Surprisingly, observing civic participation was positively related to uncivil participation (H6). Observing offensive speech was not related to uncivil participation, but experiences of both hate speech $(\mathrm{H} 7)$ and personal victimisation increased the likelihood of uncivil participation (H8). Table 4 shows the results of this last block. The full table is provided in the Supplementary File (see Table B in the Supplementary File). 
Table 3. Correlates of uncivil participation.

\begin{tabular}{|c|c|c|}
\hline & & Pearson correlation with uncivil participation \\
\hline \multirow[t]{7}{*}{ Socio-demographics } & Age & $-0.20 * *$ \\
\hline & Male & $0.07 * *$ \\
\hline & Low formal education & -0.01 \\
\hline & High formal education & $-0.05^{*}$ \\
\hline & Low income & -0.01 \\
\hline & High income & $-0.04 *$ \\
\hline & East Germany & -0.01 \\
\hline \multirow[t]{13}{*}{ Personality system } & Machiavellianism & $0.33^{* *}$ \\
\hline & Psychopathy & $0.33^{* *}$ \\
\hline & Narcissism & $0.24 * *$ \\
\hline & AFD & $0.08 * *$ \\
\hline & CDU & -0.02 \\
\hline & CSU & -0.01 \\
\hline & SPD & 0.02 \\
\hline & Green & -0.01 \\
\hline & Left & -0.01 \\
\hline & FDP & -0.01 \\
\hline & Extreme political leanings & 0.01 \\
\hline & Political anger & $0.11^{* *}$ \\
\hline & Political inefficacy & 0.01 \\
\hline \multirow[t]{12}{*}{ Social-environment variables } & Internet use per day & -0.03 \\
\hline & Social-media use & $0.12^{* *}$ \\
\hline & Facebook & $0.09 * *$ \\
\hline & Odnoklassniki & $0.14^{* *}$ \\
\hline & Twitter & $0.12 * *$ \\
\hline & VKontakte & $0.17^{* *}$ \\
\hline & Instagram & $0.17^{* *}$ \\
\hline & Pinterest & $0.08 * *$ \\
\hline & Tumblr & $0.14^{* *}$ \\
\hline & Reddit & $0.16^{* *}$ \\
\hline & Xing & $0.11 * *$ \\
\hline & Linkedin & $0.11^{* *}$ \\
\hline \multirow[t]{4}{*}{ Perceived environment } & Civil speech & $0.15^{* *}$ \\
\hline & Offensive speech & $0.05^{* *}$ \\
\hline & Hate speech & $0.28 * *$ \\
\hline & Victimisation & $0.39 * *$ \\
\hline
\end{tabular}

Notes: ${ }^{* *} \mathrm{p}<0.001,{ }^{* *} \mathrm{p} \leq 0.01, * \mathrm{p}<0.05$.

\section{Discussion}

Our study examined uncivil participation from a problem-behaviour perspective. In line with problematic behaviour theory (Jessor, 1991; Jessor \& Jessor, 1977), uncivil participation was predicted by a combination of the participants' 'personality system,' the online 'social system,' and participants' experiences in and perceptions of this online realm (see Figure 1).

First, our data showed that uncivil participation, when measured by behavioural indicators, is much more frequent than direct questions regarding hate-spreading suggest (Isenberg, 2019). Nearly half of those who had witnessed incivility had contributed to its spread, corresponding to roughly one quarter of the German online users. As the data for this study were collected in 2017, the concrete percentages must be interpreted with care. Nevertheless, long-term comparisons show that Germans witnessed more hate speech in 2020 than three years earlier (Landesanstalt für Medien NRW, 2020). In light of the observed relationship between witnessing hate speech and uncivil participation, our results can thus be considered a conservative estimate for uncivil participation in 2020. Although our measure of uncivil behaviours included both mild and more severe forms of attacks against others-and the most extreme attacks 
Table 4. Hierarchical logistic regression analysis, Block 6.

\begin{tabular}{|c|c|c|c|c|c|}
\hline & $B$ & $S E$ & OR & LL & UL \\
\hline Intercept & -2.00 & $0.23 * * *$ & 0.14 & 0.09 & 0.21 \\
\hline Age & -0.01 & 0.00 & 0.99 & 0.99 & 1.00 \\
\hline Male & 0.18 & 0.10 & 1.19 & 0.98 & 1.45 \\
\hline High education & -0.17 & 0.11 & 0.84 & 0.68 & 1.04 \\
\hline Machiavellianism & 0.30 & $0.07 * * *$ & 1.35 & 1.17 & 1.55 \\
\hline Psychopathy & 0.29 & $0.07 * * *$ & 1.33 & 1.17 & 1.52 \\
\hline Narcissism & 0.04 & 0.06 & 1.04 & 0.93 & 1.17 \\
\hline AFD & 0.41 & $0.16 * *$ & 1.51 & 1.10 & 2.06 \\
\hline CDU & 0.04 & 0.15 & 1.04 & 0.78 & 1.38 \\
\hline CSU & -0.04 & 0.24 & 0.96 & 0.60 & 1.53 \\
\hline SPD & 0.20 & 0.14 & 1.22 & 0.92 & 1.61 \\
\hline Green & 0.05 & 0.19 & 1.05 & 0.72 & 1.52 \\
\hline Left & 0.09 & 0.17 & 1.09 & 0.79 & 1.53 \\
\hline FDP & -0.07 & 0.19 & 0.94 & 0.65 & 1.34 \\
\hline Extreme political leanings & -0.02 & 0.04 & 0.98 & 0.91 & 1.06 \\
\hline Political anger & 0.10 & 0.05 & 1.11 & 1.00 & 1.23 \\
\hline Political inefficacy & 0.04 & 0.05 & 1.04 & 0.94 & 1.14 \\
\hline Internet use (hrs/d) & -0.02 & 0.02 & 0.98 & 0.95 & 1.02 \\
\hline Social-media use & 0.13 & $0.05 * * *$ & 1.14 & 1.04 & 1.25 \\
\hline Facebook & 0.01 & 0.12 & 1.01 & 0.80 & 1.29 \\
\hline Odnoklassniki & 0.29 & 0.34 & 1.34 & 0.69 & 2.64 \\
\hline Twitter & -0.08 & 0.12 & 0.92 & 0.72 & 1.17 \\
\hline Vkontakte & 1.04 & $0.40 * *$ & 2.83 & 1.33 & 6.57 \\
\hline Instagram & 0.19 & 0.12 & 1.21 & 0.96 & 1.52 \\
\hline Pinterest & 0.05 & 0.12 & 1.05 & 0.83 & 1.32 \\
\hline Tumblr & -0.09 & 0.24 & 0.91 & 0.58 & 1.45 \\
\hline Reddit & 0.35 & 0.33 & 1.42 & 0.76 & 2.76 \\
\hline Xing & 0.23 & 0.14 & 1.26 & 0.96 & 1.65 \\
\hline LinkedIn & -0.07 & 0.19 & 0.93 & 0.64 & 1.35 \\
\hline Civic speech & 0.46 & $0.15 * * *$ & 1.59 & 1.18 & 2.16 \\
\hline Offensive speech & 0.02 & 0.14 & 1.02 & 0.77 & 1.35 \\
\hline Hate speech & 1.04 & $0.12 * * *$ & 2.83 & 2.26 & 3.55 \\
\hline Victimisation & 1.23 & $0.10 * * *$ & 3.42 & 2.78 & 4.20 \\
\hline Nagelkerke's Pseudo- $R^{2}$ & \multicolumn{5}{|c|}{$0.34 * * *$} \\
\hline
\end{tabular}

Notes. ${ }^{* *} \mathrm{p}<0.001,{ }^{* *} \mathrm{p} \leq 0.01,{ }^{*} \mathrm{p}<0.05$.

are usually being driven by very few users (Kreißel et al., 2018)-our results show the larger context in which incivility flourishes.

The association between users' personal characteristics and uncivil participation was overall relatively weak. In line with prior research about dark personalities' uncivil behaviour (Kurek et al., 2019), we found that psychopathy and Machiavellianism increased self-reported uncivil participation (RQ1), whereas narcissism did not. When participants scored one scale point above average on the dark triad, they were roughly $20 \%$ more likely to engage in uncivil participation. This modest effect size could also explain why other studies with fewer participants failed to find a link between the dark triad and uncivil participation intentions (Koban et al., 2018).

In line with prior research linking the spread of uncivility and hate in Germany to the AfD (Kreißel et al.,
2018), the participants intending to vote for AfD were $50 \%$ more likely to report uncivil participation $(\mathrm{H} 2)$. We did not find any statistically significant associations between uncivil participation and the intention to vote for any of the other major parties. In contrast to prior correlational studies (Suhay et al., 2015), extreme political leanings were not linked to uncivil participation $(\mathrm{H} 1)$, suggesting that incivility, at least in Germany, is asymmetrically more compatible with right-wing as compared to (extreme) left-wing ideologies.

We did not observe a statistically significant link between participants' feelings of political anger $(\mathrm{H} 3)$ or political inefficacy $(\mathrm{H} 4)$ and uncivil participation. Uncivil participation, at least in our sample, cannot be understood as a participation driven by feelings of anger and inefficacy towards the political system. Notably, prior research found that incivility by an opposing 
party does create anger, consequently fuelling incivility (Gervais, 2016, 2019); therefore, a more nuanced understanding of the roots of political anger and its effects on uncivil online discourses would be a valuable avenue for future research.

In line with prior research (Costello et al., 2019; Koban et al., 2018; Oksanen et al., 2014), we found that social-media use (H5) was associated with uncivil participation, whereas general Internet use was not. Particularly users of the Russian-based network VKontakte, which has gained public attention for having lax moderation rules and hosting ultra-right-wing content (Udupa et al., 2020), reported uncivil participation in our study, suggesting that such platforms might be an attractive environment for those engaging in uncivil participation (RQ2).

Only partially confirming our expectations, experiences with both uncivil (H7) but also civil speech (H6) predicted higher levels of uncivil participation, although the effect for hate speech was substantially stronger. Participants who witnessed civil speech were 1.5 times more likely to report uncivil participation, but those who had noted hate speech were nearly three times as likely to report engaging in uncivil behaviour online. In line with prior research on bullying (Lee et al., 2019) and studies on the toxic effects of having been victimised (Davis et al., 2020), the participants who had been personally victimised were 3.4 times as likely to report uncivil participation $(\mathrm{H} 8)$ compared to those without such experiences.

Taken together, our data add to the theoretical understanding of uncivil participation in numerous ways. First of all, our study confirmed the central assumption of problematic behaviour theory for norm-deviant online behaviour, showing that the 'personality system,' the online environment, and the experiences within this environment jointly contribute to uncivil participation. Regarding the 'personality system,' our data did not find meaningful associations between uncivil participation and extreme political leanings, political anger, or political inefficacy. Overall, uncivil participation in the German population was not driven by these motives. We did, however, find uncivil participation to be rooted in sinister personality traits and to be prevalent among rightleaning voters.

With regard to the digital 'social system,' general Internet use did not increase the likelihood of uncivil participation, while social media was associated with uncivil participation. We did not find a statistically significant association between observing offensive speech and uncivil participation. Instead, the toxic effects of incivility were mostly related to hate speech-that is, to violations of 'public norms' that are foundational to a democratic society as Muddiman (2017) has summarised the matter. Although offensive speech can trigger nasty replies (Ziegele, Jost, Bohrmann, \& Heinbach, 2018), our data show that hate speech is the kind of discourse that is likely to erode civil discussion norms (see
Papacharissi, 2004, for a similar argument) and might need counterstrategies. Noteworthy, counter-measures such as removing content thereby must be carefully balanced against values of free speech (Masullo Chen, Muddiman, Wilner, Pariser, \& Stroud, 2019).

When it comes to concrete steps to counter hate speech, our results suggest that interventions need to account for both users' personalities and their online environments. At the level of the 'personality system,' our results are compatible with the argument that empathy might prevent the spread of incivility (Bilewicz \& Soral, 2020). Diminished empathy is the defining characteristic of the dark-triad personalities (Paulhus \& Williams, 2002; Raskin \& Hall, 1981), and fostering empathy can improve prejudiced intergroup attitudes (Batson \& Ahmad, 2009). Fostering empathy thus seems to be a promising approach to fighting the roots of incivility at the level of the 'personality system.'

At the same time, the strongest predictors for uncivil participation were related to the 'social system' and the participants' experiences therein. Using social media sites known to tolerate hateful rhetoric and experiencing hate speech and personal attacks substantially increased the likelihood of reporting uncivil participation. Therefore, our data underline the need for proprietors of online spaces and platforms to care for the spaces they provide. Research has shown that community management upholding civil norms can be a valuable strategy to accomplish this (Ziegele, Jost, et al., 2018; Ziegele, Jost, Frieß, \& Naab, 2019).

\subsection{Limitations and Further Research Directions}

Our study had several limitations that must be considered. First, we focused on Germany, a country where harsh forms of incivility are legally sanctioned. The generalisation of our findings to other cultural contexts is a question for future research. Second, we used a crosssectional design. Although this allowed us to collect a sample large enough to detect uncivil participation, the reported associations cannot be interpreted causally. Even when we think that it is most plausible that, for instance, personality predicts behaviour, long-term measurements are needed to disentangle the direction of the relationships reported in our study. Furthermore, our sample was slightly more educated than the general population. Although this reflects a typical online public and is thus suitable to study online incivility, future research on the roots of incivility amongst those with lower levels of formal education would be worthwhile. Finally, we focused on self-reported behaviours. Although our prevalence rates by far exceed prior work using definitionbased approaches, supporting the notion that behaviourbased approaches might be less susceptible to socialdesirability biases (Festl, 2016), it would be beneficial if future research were to combine our findings with observational data. 


\subsection{Conclusion}

Overall, our study confirmed the central assumption of problematic behaviour theory for uncivil participation, showing that the 'personality system,' the online environment, and the experiences therein jointly contribute to our understanding of norm-transgressing dark participation. As such, we have provided unique empirical evidence for the ongoing debate about addressing the downsides of participatory online media by highlighting the factors that contribute to the spread of incivility.

\section{Acknowledgments}

Data collection for this study was supported by the Federal Ministry of Education and Research (BMBF) via the grant number 16KIS0496, "PropStop: Detection, Proof, and Combating of Hidden Propaganda Attacks via Online Media." Kantar-Emnid Germany conducted the data collection. The first and second author are supported by the Digital Society research program funded by the Ministry of Culture and Science of the German State of North Rhine-Westphalia via the grant number 005-1709-001. We further thank the anonymous editor and the two reviewers for their constructive feedback and support throughout the review process.

\section{Conflict of Interests}

The authors declare no conflict of interest.

\section{Supplementary Material}

Supplementary material for this article is available online in the format provided by the author (unedited).

\section{References}

Barnidge, M., Kim, B., Sherrill, L. A., Luknar, Ž., \& Zhang, J. (2019). Perceived exposure to and avoidance of hate speech in various communication settings. Telematics and Informatics, 44, 1-13. https://doi.org/10/ gghenr

Batson, C. D., \& Ahmad, N. Y. (2009). Using empathy to improve intergroup attitudes and relations. Social Issues and Policy Review, 3(1), 141-177. https://doi. org/10.1111/j.1751-2409.2009.01013.x

Becker, J. C., \& Tausch, N. (2015). A dynamic model of engagement in normative and non-normative collective action: Psychological antecedents, consequences, and barriers. European Review of Social Psychology, 26(1), 43-92. https://doi.org/10/gf3gvc

Bilewicz, M., \& Soral, W. (2020). Hate speech epidemic: The dynamic effects of derogatory language on intergroup relations and political radicalization. Political Psychology, 41(1). https://doi.org/10/gg4whj

Buckels, E. E., Trapnell, P. D., \& Paulhus, D. L. (2014). Trolls just want to have fun. Personality and Indi- vidual Differences, 67, 97-102. https://doi.org/10/ f58bzw

Coe, K., Kenski, K., \& Rains, S. A. (2014). Online and uncivil? Patterns and determinants of incivility in newspaper website comments. Journal of Communication, 64(4), 658-679. https://doi.org/10/f6dxrx

Costello, M., Barrett-Fox, R., Bernatzky, C., Hawdon, J., \& Mendes, K. (2020). Predictors of viewing online extremism among America's youth. Youth and Society, 52(5), 710-727. https://doi.org/10/gf3gq3

Costello, M., Hawdon, J., Bernatzky, C., \& Mendes, K. (2019). Social group identity and perceptions of online hate. Sociological Inquiry, 89(3), 427-452. https://doi.org/10/gghcnc

Davis, J. P., Ingram, K. M., Merrin, G. J., \& Espelage, D. L. (2020). Exposure to parental and community violence and the relationship to bullying perpetration and victimization among early adolescents: A parallel process growth mixture latent transition analysis. Scandinavian Journal of Psychology, 61(1), 77-89. https://doi.org/10/ggs53d

De Leo, J. A., \& Wulfert, E. (2013). Problematic Internet use and other risky behaviors in college students: An application of problem-behavior theory. Psychology of Addictive Behaviors, 27(1), 133-141. https:// doi.org/10.1037/a0030823

dpa. (2018, August 7.). "Asyltourismus»: Söder verteidigt Begriff ["Asylum tourist": Söder defends the term]. Welt Online. Retrieved from https:// www.welt.de/regionales/bayern/article178969630/ Asyltourismus-Soeder-verteidigt-Begriff.html

Erjavec, K., \& Kovačič, M. P. (2012). "You don't understand, this is a new war!" Analysis of hate speech in news web sites' comments. Mass Communication and Society, 15(6), 899-920. https://doi.org/10/ gfgnmm

Ferguson, C. J., Cruz, A. M., Martinez, D., Rueda, S. M., Ferguson, D. E., \& Negy, C. (2008). Personality, parental, and media influences on aggressive personality and violent crime in young adults. Journal of Aggression, Maltreatment \& Trauma, 17(4), 395-414. https://doi.org/10/bbc4pg

Festl, R. (2016). Perpetrators on the Internet: Analyzing individual and structural explanation factors of cyberbullying in school context. Computers in Human Behavior, 59, 237-248. https://doi.org/10/f8hw28

Finkel, S. E. (1985). Reciprocal effects of participation and political efficacy: A panel analysis. American Journal of Political Science, 29(4), 891-913. https://doi.org/ 10/fg9xv5

Fischer, A. H., Halperin, E., Canetti, D., \& Jasini, A. (2018). Why we hate. Emotion Review, 10(4), 309-320. https://doi.org/doi/10.1177/1754073917751229

Gagliardone, I., Pohjonen, M., Zerai, A., Beyene, Z., Aynekulu, G., Bright, J., . . . \& Teferra, Z. M. (2016). Mechachal: Online debates and elections in Ethiopia-From hate speech to engagement in social media. Oxford: University of Oxford. 
Garland, J., Ghazi-Zahedi, K., Young, J.-G., HébertDufresne, L., \& Galesic, M. (2020). Countering hate on social media: Large scale classification of hate and counter speech. arXiv.org. Retrieved from http:// arxiv.org/abs/2006.01974

Gervais, B. T. (2016). More than mimicry? The role of anger in uncivil reactions to elite political incivility. International Journal of Public Opinion Research, 29(3), 384-405. https://doi.org/10/gftpws

Gervais, B. T. (2019). Rousing the partisan combatant: Elite incivility, anger, and antideliberative attitudes. Political Psychology, 40(3), 637-655. https://doi.org/ 10/gghens

Geschke, D., Klaßen, A., Quent, M., \& Richter, C. (2019). Hass im Netz: Der schleichende Angriff auf unsere Demokratie [Hate on the net: The creeping attack on our democracy]. Jena: Institut für Demokratie und Zivilgesellschaft.

Hays, R. D., Stacy, A. W., \& di Matteo, M. R. (1987). Problem behavior theory and adolescent alcohol use. Addictive Behaviors, 12(2), 189-193. https://doi.org/10.1016/0306-4603(87)90026-8

Herbst, S. (2010). Rude democracy: Civility and incivility in American politics. Philadelphia, PA: Temple University Press.

Hine, G. E., Onaolapo, J., De Cristofaro, E., Kourtellis, N., Leontiadis, I., Samaras, R., . . \& B Blackburn, J. (2016). Kek, cucks, and god emperor Trump: A measurement study of 4chan's politically incorrect forum and its effects on the Web. arXiv.org. Retrieved from http:// arxiv.org/abs/1610.03452

Hsueh, M., Yogeeswaran, K., \& Malinen, S. (2015). "Leave your comment below": Can biased online comments influence our own prejudicial attitudes and behaviors? Human Communication Research, 41(4), 557-576. https://doi.org/10.1111/hcre.12059

Hwang, H., Kim, Y., \& Huh, C. U. (2014). Seeing is believing: Effects of uncivil online debate on political polarization and expectations of deliberation. Journal of Broadcasting \& Electronic Media, 58(4), 621-633. https://doi.org/10/gf3g62

Isenberg, M. (2019). Hate speech und Diskussionsbeteiligung im Netz [Hate speech and involvement in discussions on the net]. Landesanstalt für Medien NRW. Retrieved from https://www.medienanstaltnrw.de/fileadmin/user_upload/Ifm-nrw/Service/ Veranstaltungen_und_Preise/Ergebnisbericht_ Hate_Speech_Sonderstudie_LFMNRW.pdf

Jaki, S., \& Smedt, T. D. (2019). Right-wing German hate speech on Twitter: Analysis and automatic detection. arXiv.org. Retrieved from http://arxiv.org/abs/1910. 07518

Jessor, R. (1991). Risk behaviour in adolescents: A psychosocial framework for understanding and action. Journal of Adolescent Health, 12, 597-695. https:// doi.org/10.1016/1054-139X(91)90007-K

Jessor, R. (2014). Problem behavior theory: A halfcentury of research on adolescent behavior and development. In R. M. Lerner, A. C. Petersen, R. K. Silbereisen, \& J. Brooks-Gunn (Eds.), The developmental science of adolescence: History through autobiography (pp. 239-256). New York, NY: Psychology Press.

Jessor, R. (2017). Problem drinking and psychosocial development in adolescence. In R. Jessor (Ed.), Problem behavior theory and adolescent health: The collected works of Richard Jessor (Vol. 2, pp. 105-121). Wiesbaden: Springer. https://doi.org/10.1007/9783-319-51349-2_6

Jessor, R., \& Jessor, S. (1977). Problem behavior and psychosocial development: A longitudinal study of youth. Cambridge: Academic Press. Retrieved from https://www.scienceopen.com/document?vid= 75f5b901-e506-4382-8d2d-307b63a5b851

Jost, J. T. (2017). Asymmetries abound: Ideological differences in emotion, partisanship, motivated reasoning, social network structure, and political trust. Journal of Consumer Psychology, 27(4), 546-553. https:// doi.org/10/gdh72z

Kenski, K., Coe, K., \& Rains, S. A. (2020). Perceptions of uncivil discourse online: An examination of types and predictors. Communication Research, 47(6), 795-814. https://doi.org/10/gghcnf

Koban, K., Stein, J. P., Eckhardt, V., \& Ohler, P. (2018). Quid pro quo in Web 2.0: Connecting personality traits and Facebook usage intensity to uncivil commenting intentions in public online discussions. Computers in Human Behavior, 79, 9-18. https://doi.org/ 10/gf3gv4

Kreißel, P., Ebner, J., Urban, A., \& Guhl, J. (2018). Hass auf Knopfdruck: Rechtsextreme Trollfabriken und das Ökosystem koordinierter Hasskampagnen im Netz [Hate when the button is pressed: Right-wing extremist troll fabrics and the ecosystem of coordinated hate campaigns in the Internet]. London: Institute for Strategic Dialogue.

Küfner, A. C. P., Dufner, M., \& Back, M. D. (2014). Das dreckige Dutzend und die niederträchtigen Neun: Kurzskalen zur erfassung von Narzissmus, Machiavellismus und Psychopathie [The dirty dozen and the naughty nine: Short scales for measuring narcissicm, Marchiavellism, and psychopathy]. Diagnostica, 61(2), 76-91. https://doi.org/10/gf3gzv

Kümpel, A. S., \& Rieger, D. (2019). Wandel der Sprach: und Debattenkultur in sozialen Online Medien. Ein Literaturüberblick zu Ursachen und Wirkungen von inziviler Kommunikation [Changing debate cultures in social online media: A literature review on the causes and consequences of uncivil communication]. Berlin: Konrad-Adenauer Stiftung.

Kurek, A., Jose, P. E., \& Stuart, J. (2019). ‘I did it for the LULZ': How the dark personality predicts online disinhibition and aggressive online behavior in adolescence. Computers in Human Behavior, 98, 31-40. https://doi.org/10/ggft9d

Landesanstalt für Medien NRW. (2020). forsa-Befragung zu: Hate Speech 2020 [forsa survey on: Hate 
speech 2020]. Düsseldorf: Landesanstalt für Medien NRW. Retrieved from https://www.medienanstaltnrw.de/fileadmin/user_upload/NeueWebsite_0120/ Themen/Hass/forsa_LFMNRW_Hassrede2020_ Ergebnisbericht.pdf

Lee, J. M., Kim, J., Hong, J. S., \& Marsack-Topolewski, C. N. (2019). From bully victimization to aggressive behavior: Applying the problem behavior theory, theory of stress and coping, and general strain theory to explore potential pathways. Journal of Interpersonal Violence. Advance online publication. https:// doi.org/10.1177/0886260519884679

Masullo Chen, G., Muddiman, A., Wilner, T., Pariser, E., \& Stroud, N. J. (2019). We should not get rid of incivility online. Social Media + Society, 5(3). https://doi.org/ 10/gghcnh

Muddiman, A. (2017). Personal and public levels of political incivility. International Journal of Communication, 11, 3182-3202.

Mutz, D. C. (2015). In-your-face politics: The consequences of uncivil media. New Jersey, NY: Princeton University Press.

Nabi, R. L. (2002). Anger, fear, uncertainty, and attitudes: A test of the cognitive-functional model. Communication Monographs, 69(3), 204-216.

Näsi, M., Räsänen, P., Hawdon, J., Holkeri, E., \& Oksanen, A. (2015). Exposure to online hate material and social trust among Finnish youth. Information Technology \& People, 28(3), 607-622. https://doi.org/10.1108/ITP09-2014-0198

O'Sullivan, P. B., \& Flanagin, A. J. (2003). Reconceptualizing "flaming" and other problematic messages. New Media \& Society, 5(2), 69-94. https://doi.org/ 10/b3txz4

Oksanen, A., Hawdon, J., Holkeri, E., Näsi, M., \& Räsänen, P. (2014). Exposure to online hate among young social media users. In N. M. Warehime (Ed.), Soul of society: A focus on the lives of children \& youth (pp. 253-274). Oklahoma City, OK: Emerald Books.

Papacharissi, Z. (2004). Democracy online: Civility, politeness, and the democratic potential of online political discussion groups. New Media \& Society, 6(2), 259-283. https://doi.org/10/dz4rp6

Paulhus, D. L., \& Williams, K. M. (2002). The dark triad of personality: Narcissism, Machiavellianism, and psychopathy. Journal of Research in Personality, 36(6), 556-563. https://doi.org/10/d2jxm9

Postmes, T., Spears, R., \& Lea, M. (1998). Breaching or building social boundaries? SIDE-effects of computermediated communication. Communication Research, 25(6), 689-715. https://doi.org/10/ffsbdn

Quandt, T. (2018). Dark participation: Manipulative user engagement in the news making process. Media and Communication, 6(4), 36-48. http://dx.doi.org/ 10.17645/mac.v6i4.1519

Raskin, R., \& Hall, C. S. (1981). The narcissistic personality inventory: Alternate form reliability and further evidence of construct validity. Journal of Personal- ity Assessment, 45(2), 159-162. https://doi.org/10/ ch4b6b

Reinemann, C., Ninierza, A., Fawzi, N., Riesmeyer, C., \& Neumann, K. (2019). Jugend-MedienExtremismus [Youth-Media-Extremism]. Wiesbaden: Springer Fachmedien VS.

Schröder, J. (2016, December 1). Die 20 populärsten sozialen Netzwerke in Deutschland [The 20 most popular social network sites in Germny]. Meedia.de. Retrieved from https://meedia.de/2016/ 12/01/die-20-populaersten-sozialen-netzwerkein-deutschland-facebook-klar-vorn-instagramsnapchat-und-musical-ly-boomen

Shane, P. M. (2004). Democracy online: The prospects for political renewal through the Internet. New York, NY: Psychology Press.

Silva, L., Mondal, M., Correa, D., Benevenuto, F., \& Weber, I. (2016). Analyzing the targets of hate in online social media. arXiv.org. Retrieved from http:// arxiv.org/abs/1603.07709

Statistisches Bundesamt. (2020). Private Haushalte in der Informationsgesellschaft: Nutzung von Informationsund Kommunikationstechnologien [Private households in the information society: Use of information and communication technologies] (No. 15-4). Wiesbaden: Statistisches Bundesamt.

Stekhoven, D. J., \& Buehlmann, P. (2012). MissForest: Non-parametric missing value imputation for mixedtype data. Bioinformatics, 28(1), 112-118.

Stroud, N. J. (2010). Polarization and partisan selective exposure. Journal of Communication, 60(3), 556-576. https://doi.org/10/d6p3kx

Stürmer, S., \& Simon, B. (2009). Pathways to collective protest: Calculation, identification, or emotion? A critical analysis of the role of group-based anger in social movement participation. Journal of Social Issues, 65(4), 681-705. https://doi.org/10/d3nfv3

Suhay, E., Blackwell, A., Roche, C., \& Bruggeman, L. (2015). Forging bonds and burning bridges: Polarization and incivility in blog discussions about occupy wall street. American Politics Research, 43(4), 643-679. https://doi.org/10.1177/1532673X1455 3834

van Geel, M., Goemans, A., Toprak, F., \& Vedder, P. (2017). Which personality traits are related to traditional bullying and cyberbullying? A study with the Big Five, Dark Triad and sadism. Personality and Individual Differences, 106, 231-235. https://doi.org/10/ f9g9n6

Webster, G., \& Jonason, P. (2013). Putting the "IRT" in "Dirty": Item response theory analyses of the Dark Triad Dirty Dozen: An efficient measure of narcissism, psychopathy, and Machiavellianism. Personality and Individual Differences, 54(2), 302-306. https://doi. org/10/gg8hm2

Zick, A., Küpper, B., \& Hövermann, A. (2011). Die Abwertung der Anderen. Eine europäische Zustandsbeschreibung zu Intoleranz, Vorurteilen und Diskri- 
minierung [The derogation of others: A European description of the state of intolerance, prejudice, and discrimination]. Berlin: Friedrich Ebert Foundation.

Ziegele, M., Jost, P., Bormann, M., \& Heinbach, D. (2018). Journalistic counter-voices in comment sections: Patterns, determinants, and potential consequences of interactive moderation of uncivil user comments. Studies in Communication and Media, 7(4), 525-554. https://doi.org/10/gf3gk2

Ziegele, M., Jost, P., Frieß, D., \& Naab, T. (2019). Aufräumen im Trollhaus: Zum Einfluss von Community-
Managern und Aktionsgruppen in Kommentarspalten [Tidy up the troll house: On the influence of community managers and activist groups in the comment sections] Düsseldorf: Institute for Internet and Democracy.

Ziegele, M., Koehler, C., \& Weber, M. (2018). Socially destructive? Effects of negative and hateful user comments on readers' donation behavior toward refugees and homeless persons. Journal of Broadcasting \& Electronic Media, 62(4), 636-653. https:// doi.org/10/gf8pn4

\section{About the Authors}
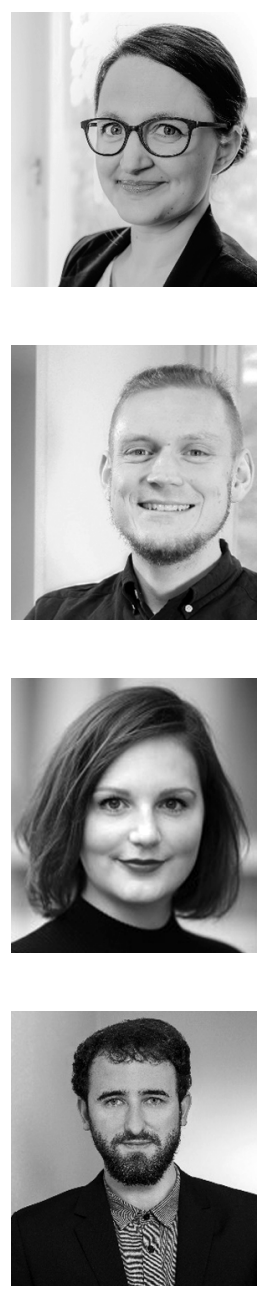

Lena Frischlich (PhD) is currently an Interim Professor at the LMU Munich, Department of Communication and Media Studies and the Principal Investigator of the junior research group 'Democratic Resilience in Times of Online Propaganda, Fake News, Fear and HateSpeech (DemoRESILdigital)' at the University of Münster, Institute for Communication Science. Her research interests include the staging and effects of online-propaganda and related phenomena in a changing media environment and digital communication more broadly.

Tim Schatto-Eckrodt is a Research Associate at the Department of Communication at the University of Münster, Germany. He holds an MA degree in Communication Studies from the same department. He is currently working on his PhD project about online conspiracy theories and is part of the junior research group 'Democratic Resilience in Times of Online Propaganda, Fake News, Fear and HateSpeech (DemoRESILdigital).' His further research interests include computational methods and online propaganda.

Svenja Boberg is a Communication Scientist at the University of Münster, who researches the dynamics of online debates and social media hypes using computational methods. In her dissertation she studies the spread of outrage in social media networks. In 2016 she joined the BMBF-funded project 'Detection, Proof and Combating of Covert Propaganda Attacks via Online Media.' Beforehand, she completed her MA in Communication Studies at the University of Münster addressing news consumption on Facebook.

Florian Wintterlin (PhD) is a Research Associate at the University of Münster. After finishing his $\mathrm{PhD}$ in trust and journalism research, he worked on disinformation in the BMBF-funded project 'Detection, Proof and Combating of Covert Propaganda Attacks via Online Media.' Currently, his research includes questions of science communication as well as political communication with a focus on digital phenomena. 